the acid finds its way around the base of the teeth, where it does the harm we refer to. Rinsing the mouth with alkaline solutions does not meet the case, but rather complicates it. Most patients are not disposed to endure such an additional ordeal, and the want of sufficient scrupulousness in the matter superinduces the damage any way. I believe that the interests involved, both as to the preservation of tissue as well as to the maintenance of comfort to the patient, demand that we devise a method of drug administration that shall be genuinely protective and tolerable.
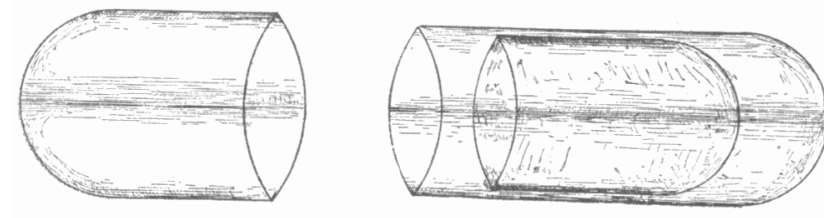

Fig. 3.-Inner capsule partially inserted.

I wish to submit a suggestion with regard to the administration of hydrochloric acid, which my personal experience has shown meets the difficulties with the best resulte. In prescribing the acid, I at first suggested to my patients that they take it in gelatin capsules. I found, however, that the acid penetrates the capsule quite quickly. After repeated trials I found that two capsules, so arranged that a smaller containing the drug, was encased by a larger one, would give sufficient thickness to obviate the diffi. culty of quick penetration, and would, in fact, retain the drug for a long time. It gives the patient ample time for swallowing and reduces whatever annoyance or risk is involved to a minimum. The double capsule is easily constructed. The cap of an "O" capsule
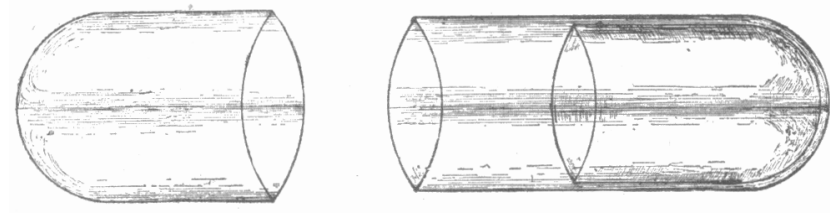

Fig. 4.-Inner capsule in proper position.

will fit into the bottom of an "OO" capsule, and forms with it a bottom of double thickness, and offers, therefore, a twofold resistance to the action of the acid. Similarly with the other half of the capsule. The patient is instructed to use an ordinary dropper for filling the capsule, immediately before taking. Such double-bottomed capsule can hold fifteen minims of hydrochloric acid.

I have used this method of administration for some time and have found it practicable and acceptable to patients.

Parke, Davis \& Co. have devised apparatus for the manufacture of these capsules at a slight advance over the price of the ordinary gelatin capsules.

32 Adams Ave. West.

Experimental Research in Regard to Infiltration Anesthesia.Heinze and Braun report extensive personal teste on the various anesthetics employed for infiltration. They reject all the formule in vogue, for one reason or another, and propose the following as a solution that fulfils all the conditions required in infiltration anesthesia : 0.05 to 0.2 per cent. cocain in 0.8 per cent. salt solution at the temperature of the body.-Virchow's Archiv (Berlin), cliii, 3.

\section{ACUTE ANGINA.}

REPORT OF CASE FROM WHICH THE MICROCOCCUS TETRAgENUS WAS ISOLATED IN PURE CULTURE.

BY AUGUST JEROME LARTIGAU, M.D.

Assistant in Pathology and Bacteriology, Bender Hygienic Laboratory; Pathologist to Child's Hospital; and

ANDREW MACFARLANE M.D.

Clinical Professor, Albany Medical College; Visiting Physician to Albany Orphan Asylum. ALBANY, $N$. $x$.

More and more attention is being directed to the pathogenesis of the micrococcus tetragenus in human pathology through the increasing observations of recent years upon this subject. Until lately it had been regarded purely as a saprophyte of little importance; but the bacteriologic studies of investigators in the domain of clinic medicine point very conclusively to the pathogenic rôle of this organism from time to time in the human subject, generally as processes more or less localized in their nature, less often in the form of systemic invasion. The conception of the possible pathogenesis for human beings is to a considerable extent largely the outcome of the investigations of Chauffard and Raymond, Lepage and Bezançon, ${ }^{2}$ A. Bertaux, ${ }^{3}$ J. Castaigne, ${ }^{4}$ Carrier ${ }^{5}$ and others.

Notwithstanding the fact that the micrococcus tetragenus has already been associated with a considerable number of varied lesions, the reports of instances of tetragenic infection of the throat are small in number. Apert, ${ }^{6}$ in the early part of last year, reported three cases of this nature, two of which were conclusive examples. One of the writers ${ }^{7}$ later added three cases to this list; and as far as known to us these are the only cases referred to in literature in which the tetragenococcus has been recognized as bearing a casual relation to some types of acute angina.

The following case came under the observation of one of us about a year ago:

H. L., 27 years of age, physician, was taken ill on March 11, 1898. His family history was unimportant. As a child he suffered from some of the diseases common to that period of life. A noteworthy point in connection with past illness is the very marked tendency to cerebral symptoms-manifestations accompanying processes, often of a mild nature. For some days before the appearance of the present throat symptoms he had been suffering from diarrhea, which had weakened him considerably. On March 11, there was anorexia and headache; the succeeding day the left tonsil became swollen and painful. The next day the patient remained in bed, the temperature having reached $101 \mathrm{~F}$., and the throat became more painful, both tonsils swollen and covered with a few discrete, raised, yellowish or gray areas of membrane formation not larger than the size of a pea. The pharynx was markedly swollen. This condition continued, the temperature rising to $103 \mathrm{~F}$; the pain in the throat had become more intense and the membrane, now diffuse, was yellowish white in color, covered both tonsils, the posterior wall of the pharynx,

1 Deux cas mortels de septicémie tetraginique. Arch. de Méd. Exp. Mai, 1896 , p. 304 .

2 Miningite suppurée localisée du au M. Tetragène. Gaz. Heb. de Med. et Chir..Jan. 27, 1898

3 Pseudo-rheumatisme infectieux. Gax. Heb. de Méd. et de Chir., 2

4 Pleurísie purnlente et septicémie mortelle produites par le tetra-
$\quad$. gène. Bull. de la Soc. Anat..1897, p. 309.

5 Presse Med., Oct. $27,1898$.

1898.

Apert: Angine à tetrasine. Séance de la Soc. de Biologie, Jan 29 , 7 Lartigau: A Contribution to the Study of the Micrococeus Tetragenus in Acute Angina. Phila. Med. Jour,, A pril 22, 1899. 
and was easily detachable, leaving a bleeding surface. teristic appearance of diphtheria; at other times On the evening of the fourth day there was slight resembling tonsillitis in its common forms. The delirium, which became more severe on the following phenomena of a general systemic nature in the cases day, and finally the sixth day found the patient again thus far studied have been in a general way similar to rational. On March 16, the seventh day of the dis- those common in acute tonsillitis. The case reported ease, the membrane disappeared, the temperature was in this paper was one accompanied by profound normal and a marked amelioration was apparent. disturbances, but the cerebral symptoms are, perhaps, From this time convalescence was rapid. The treat- to be regarded in this case more of the nature of a ment consisted in the administration of trional, ice-packs to the head, and an antiseptic gargle.

A swab was taken from the throat on the third day of the disease and a culture on blood serum, prepared in the usual manner, showed a profuse growth, the cover-slips from which contained moderate-sized, oval cocci arranged almost entirely as tetrads and taking the aniline gentian violet and Loeffler's methylene blue stains evenly and deeply. A few dip. lococci of similar size could be made out. Treated with Gram's solution, the cocci retained their stain.

Agar and gelatin plates made from the blood-serum culture contained pure growths of a coccus which behaved on media as follows:

Agar slant: profuse, gray, moist, slimy growths slightly raised above the surface of the medium.

Blood-serum: a growth similar in character to that on agar.

Potato: thick, slimy, white growth.

Gelatin stab: white growth along the line of inoculation, and in three or four days a round, raised, white, button-like growth on surface; no liquefaction of the gelatin.

Faintly alkaline bouillon: very slight turbidity of the medium and a thick gray or white viscid deposit in the bottom.

Litmus milk: slight acidity but no coagulation of milk.

Dunham's solution: growth similar to that in bouillon; no indol formation.

Lactose, glucose and saccharose media: no evidences of gas production.

Hanging drop: preparations showed no motility and cover-slips from various media exhibited a variable morphology-sometimes diplococci, less often tetrads. The organism stained by Gram's method.

A full-grown guinea-pig, subcutaneously inoculated with 2 c.c. of a 24 -hour-old bouillon culture, died in four days, with abscess formation at the point of inoculation. The inoculated coccus was recovered from the abscess, blood and viscera. Four c.c. injected into one of the auricular veins of a three-quartergrown rabbit produced stupor, and death in eightyseven hours. The organism was recovered from the blood; cover-slips from the viscera, pus from abscess in guinea-pig, and the sections of tissue from the animals experimented on contained tetrad cocci in abundance.

The bacteriologic diagnosis was micrococcus tetragenus (Gaffky).

The appearance of the throat, it has been thought by Dieulafoy in some cases, is to be regarded to some extent as a characteristic of this class of infection: "Ils donnaient l'apparence d'une gorge qui aurait été scupaudrée de grains de sable," to which French observers give the name "angine sableuse."

We are constrained, however, from our experience, based on four cases of tetragenic infection, to regard the throat picture as variable in presentation, sometimes simulating the supposedly, until lately, charac-

"Apert: Soc. de Biologie, 1896.

susceptibility on the part of the patient, since in all diseases a more or less marked tendency toward cerebral derangement has been manifest.

The frequency of the localization of processes, due to infection with this organism, to the mouth and about the jaws, has already been noted by Karlinsky. ${ }^{9}$ An explanation of this may be found in the fact that the micrococcus tetragenus is commonly found in the mouths of perfectly healthy individuals, as we have repeatedly observed.

\section{EXPERIMENTS IN GASTRIC DIGESTION.*}

\author{
A PRELIMINARY REPORT. \\ BY FENTON B. TURCK, M.D. \\ Chicago.
}

The experimental study of gastric digestion of proteids has been extensively made from a chemic standpoint. Test-tube digestion by the aid of ferments has created a large literature in this branch of physiologic chemistry. Kuhne and Chittenden's classsification of digestive products or Neumeister's nomenclature are most generally adopted, and in the absence of a knowledge of the albumin molecule, serve at least for a temporary classification. Kossel's work has not led to any more definite conclusion and it may be stated that the slight differences found in the chemic reaction or the physical properties of the albumoses have not been so characteristic as to allow these compounds to be regarded as separate bodies.

The object of digestion appears to be to reduce the food to such a condition that the cells lining the walls of the intestine may take it up, change and transfer it to the blood in the form of circulating albumins. This process is very much influenced by certain mechanic or motor functions of the gastro-intestinal tract. If this function of motility is hindered or obstructed the process of digestion is very much retarded or ceases altogether.

The methods of investigation which the author has the honor of presenting before this association have for their object the observation of the influence of mechanic or motor effects on the process of gastric digestion by the use of artificially devised stomachs, made from rubber of different degrees of elasticity. These artificial stomachs are caused to imitate in some degree the movements of the normal stomach contents, the churning process by which the food is forced from one end of the stomach to the other and back again.

The artificial stomach apparatus consists of thin rubber bags suspended from an arm which moves in a half circle, so that the contents of the bags are thrown from one end to the other. These bags are placed in an incubator at the usual temperature. When thick bags, with strong elastic resistance are employed, the process is very marked, but when thin rubber bags are used in which the resistance is very

${ }_{9}^{9}$ Karlinsky: Centralb. f. Bakteriologie, 1890, vii, p. 113.

* Read before the American Gastro-Enterological Association, May, '99. 